\title{
Preface to the second special issue on Laser Ranging
}

\author{
Erricos C. Pavlis ${ }^{1} \mathbb{D} \cdot$ Vincenza Luceri $^{2} \cdot$ Toshimichi Otsubo $^{3} \cdot$ Ulrich Schreiber $^{4}$
}

Received: 20 September 2019 / Accepted: 21 September 2019 / Published online: 10 October 2019

(c) Springer-Verlag GmbH Germany, part of Springer Nature 2019

Laser technology has revolutionized scientific research and applications since the very early years after its invention (Maiman 1960). Earth and space science were the prime beneficiaries of this cutting edge research used to range to satellites and the moon within the first decade since its invention. The properties of light, namely isotropy and a constant and well-defined propagation velocity, introduced accurate long-distance ranging to geodesy. As the number and quality of the scientific products of its application rose exponentially, it became apparent that an international coordination of these activities would help maximize the return of individual country investments and further increase the areas of research. The International Laser Ranging Service (ILRS) was established by the International Association of Geodesy (IAG) in 1998 to support programs in geodesy, geophysics, fundamental physics and lunar science and to provide the International Earth Rotation and Reference Systems Service (IERS) with elements of the components required for the development and maintenance of the International Terrestrial Reference Frame (ITRF), a product that is essential for science, engineering and socioeconomic applications.

\footnotetext{
Erricos C. Pavlis

epavlis@umbc.edu

Vincenza Luceri

cinzia.luceri@e-geos.it

Toshimichi Otsubo

t.otsubo@r.hit-u.ac.jp

Ulrich Schreiber

ulrich.schreiber@tum.de

1 Joint Center of Earth Systems Technology, University of Maryland Baltimore County, 1000 Hilltop Circle, TRC \#182, Baltimore, MD 21250, USA

2 e-GEOS S.p.A., Contrada Terlecchie, 75100 Matera, Italy

3 Hitotsubashi University, Kunitachi, Tokyo, Japan

4 Technische Universität München, Geodätisches Observatorium Wettzell, 93444 Bad Kötzting, Germany
}

After a decade of existence, in late April of 2000, a session was convened within the European Geophysical Society's Symposium 'Evolving Geodesy: from static to kinematics', on 'Laser Technology', capturing the status and contributions at that point in time (Pavlis and Schreiber 2001). Now, two decades since its continuous evolution and support of scientific research, a review of its status and accomplishments is very appropriate.

This second special issue on Laser Ranging is intended to present the reader with the current status of the technique applied to earth and space science and engineering today. Roughly two dozen contributions include an overview of the ILRS today with an outlook for the future; a historical review of the early years prior to the establishment of the ILRS (Pearlman et al. 2019); a presentation of the important target satellites with significant contributions to science; a description of the ground systems comprising the current network and advanced designs for the near future; novel designs of new targets for improved data accuracy; new analysis methods and standards for increased accuracy of the products; interactions and joint projects with other techniques having common scientific goals; independent approaches in validating data accuracy; improvements in the area of network operations; an overview of the data information system that manages, supports and archives for posterity the data and products of laser ranging; and a sample lunar science applications.

Although not as complete a list of topics as we had originally envisioned, we hope that this special issue gives a good account of the state of the technique today and the vision of the community for its future. Our sincere thanks go to the many contributors who took the time to participate with their manuscripts, while most of them also offered their services as reviewers, despite their workload.

Finally, we are grateful to the editor in Chief, Jürgen Kusche, for his generous and essential support on the editorial process, from issuing the call to the final publication step. We would further like to extend our thanks to the editorial staff at the Journal of Geodesy and to our colleagues who performed the reviews for this issue. Our comparatively 
small community depends strongly on their knowledge and support for the successful realization of this special issue.

Guest Editors

Erricos C. Pavlis

Vincenza Luceri

Toshimichi Otsubo

Ulrich Schreiber

September 2019
Pavlis EC, Schreiber U (eds) (2001) Surveys in geophysics, vol 22, issue 5-6. ISSN: 0169-3298 (online)

Pearlman M, Brachet G, Lefebvre M et al (2019) The Smithsonian Astrophysical Observatory (SAO) and the Centre National d'Études Spatiales (CNES): contributions to the international laser ranging network. J Geod 93:869. https://doi.org/10.1007/ s00190-018-1209-0

\section{References}

Maiman TH (1960) Stimulated optical radiation in ruby. Nature 187(4736):493-494 